\title{
Role of Imprint and Scrape Cytology in Tumour and Tumour Like Lesions of Ovary
}

\author{
Afra Taqdees $^{1 *}$, Surekha U. Arakeri ${ }^{2}$ \\ ${ }^{1}$ Junior Resident, Department of Pathology, BLDE (Deemed to be University) Shri B. M. Patil Medical College Hospital \& \\ Research Centre, Karnataka, India \\ ${ }^{2}$ Professor and HOD, Department of Pathology, BLDE (Deemed to be University) Shri B. M. Patil Medical College Hospital \\ \& Research Centre, Karnataka, India
}

*Address for Correspondence: Dr. Afra Taqdees, Department of Pathology, BLDE (Deemed to be University) Shri B. M. Patil Medical College Hospital \& research Centre, Sholapur Road, Vijayapura, Karnataka-586103, India

E-mail: afrataqdees123@gmail.com

Received: 14 May 2020/ Revised: 22Aug 2020/ Accepted: 26 Oct 2020

\begin{abstract}
Background: Tumour and tumour like lesions of the ovary are most frequently encountered ovarian lesions. Various cytological methods such as imprint and scrape cytology can be used for quick microscopic analysis of pathological lesions and thus helps to differentiate between neoplastic and non-neoplastic conditions.

Methods: A prospective study was done on surgically resected ovarian specimens from December 2017 to June 2019 . For imprint smears, slides were gently touched on a freshly cut surface of the specimen. For scrape smears, the cut surface of the ovary was scraped with one end of the slide and smeared. These smears were fixed in $95 \%$ ethanol and stained with H \& E and PAP stain and the cyto-morphological study was done which was further correlated with histopathology diagnosis.

Results: Total 110 cases were studied, 68 cases were epithelial tumours, 18 germ cell tumours, 12 sex cord-stromal tumours, 1 case each of lymphoma and metastatic carcinoma and 10 were tumour like lesions of ovary. Cyto-histological discordance was found in 17 cases. Sensitivity, Specificity, Positive predictive value \& Accuracy of overall cytology was $88 \%, 98.7 \%, 91.6 \%$ and $91 \%$ respectively. Comparison between imprint and scrape smears was done for cyto-morphological features such as cellularity, architectural pattern, nuclear features, cyto-plasmic staining and background.

Conclusion: Scrape cytology is an efficient means of investigation having a high degree of sensitivity, specificity and accuracy as compared to imprint cytology; hence it can be used as a rapid diagnostic modality along with the frozen section in the diagnosis of tumour and tumour like lesions of ovary.
\end{abstract}

Key-words: Imprint cytology, Scrape cytology, Tumours and Tumour like lesions of ovary

\section{INTRODUCTION}

Tumour and tumour like lesions of the ovary are the most frequently encountered ovarian lesions in females. These lesions can be diagnosed preoperatively depending upon the clinical presentation of patient and radiological findings ${ }^{[1]}$. In present days, the utility of preoperative and intra-operative diagnostic cytology is increasing as the patient concern and management

\section{How to cite this article}

Taqdees A, Arakeri SU. Role of Imprint and Scrape Cytology in Tumour and Tumour Like Lesions of Ovary. SSR Inst. Int. J. Life Sci., 2020; 6(6): 2670-2677.

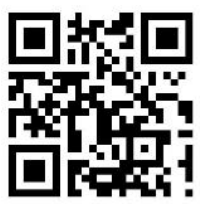

Access this article online https://iijls.com/ have become extremely individualized.

Variety of cytological techniques that are used for cytological diagnosis are fine needle aspiration cytology (FNAC), imprint smear cytology, scrape smear cytology etc ${ }^{[2,3]}$.

FNAC of superficial and deep lesions from various sites is an accepted diagnostic technique. However, its use in lesions of the ovary has been limited due to its relative inaccessibility, fear of spillover of tumour contents into peritoneal cavity or rupture of the capsule that can lead to secondary implantation and upstaging of tumour ${ }^{[4]}$. Ovarian tumours are heterogeneous and are comprised of a group of benign, borderline \& malignant tumours of epithelial, stromal and germ cell origin. Certain nonneoplastic lesions of the ovary can present as a pelvic mass and may mimic ovarian neoplasm. Proper 
intraoperative recognition of such lesions is important to plan appropriate surgical procedure ${ }^{[1]}$.

Intra-operative cytology in adjunct to frozen section study can help to differentiate non-neoplastic ovarian lesions from neoplastic lesions. Also, it helps to differentiate benign neoplasm from malignant neoplasm. Imprint and Scrape cytology are simple, rapid and reliable intra-operative cytological diagnostic modality. These techniques are easy to adopt and does not require specialized equipment or setups. Hence these techniques can be used as an adjunct to the frozen section. In scrape cytology, the cellular yield is more with better preservation of architecture and also different areas can be studied simultaneously by this technique $[2,4,5]$.

Imprint and Scrape smears can also be used for confirmation of recurrent malignancies and to determine the clearance or involvement of surgical margins and lymph nodes. Material obtained from imprint and scrape smears can also be used for flow cytometry and cytogenetic studies ${ }^{[6-8]}$.

\section{MATERIALS AND METHODS}

Type of study- Prospective study

Duration of study- 19 months ( $1^{\text {st }}$ December 2017 to $30^{\text {th }}$ June 2019).

Inclusion and Exclusion criteria- All surgically resected tumour and tumour like lesions of ovary received for histopathological examination were included in the study and completely cystic ovarian lesions without solid component were excluded from the study.

Gross examination of the surgically resected specimen of tumour and tumour like lesions of the ovary was done. Then the specimen was cut into two halves with a sharp knife/scalpel. The cut surface was gently mopped with a dry gauze or filter paper to remove the excess of blood, fluid or any cystic contents. The most appropriate and representative area was selected for imprint and scraping. For imprint smear preparation, the slide was gently touched on the freshly cut surface of the specimen, avoiding a gliding movement. For scrape smear preparation the cut surface of the ovary was scraped with one end of the slide and smear was prepared on the other slide from the scraped material. 24 smears for each case were prepared from different areas, which were immediately fixed in $95 \%$ ethyl alcohol and stained with Haematoxylin \& Eosin (H \& E) stain and
Papanicolaou (PAP) stain. Total time taken for smear preparation, staining \& reporting was about 15 minutes. Cytological evaluation of both imprint and scrape smears was done for cellularity, architecture, nuclear features, cytoplasmic features and background features. Then comparative study between imprint and scrape cytology was carried out and further histopathological correlation was done.

Statistical Analysis- All the characteristics were descriptively summarized. The summary statistics of number, mean and standard deviation were used for continuous variables. And for categorical data, the number \& percentage were used. Fisher exact test/ Chisquare $\left(\chi^{2}\right)$ was used to determine the significant difference between the imprint and scrape cytology. The mean difference was analyzed with the help of $t$-test/z test and ANOVA. If the p-value was <0.05, then the results were considered to be significant. Data were analyzed using SPSS software v.20.0.

Ethical Approval details- This study was approved by the Ethical Committee of B.L.D.E (Deemed to be) University's Shri. B. M. Patil Medical College Hospital and Research Centre, Vijayapura, Karnataka, India.

\section{RESULTS}

Total 110 cases of tumour and tumour like lesions of ovary were studied. The age group of patients in the present study ranged from 6 to 75 years with a mean age of 40.5 years. Most of the cases were seen in the age group of 21-40 years (60\%). Out of 110 cases, majority of the cases were partly solid and partly cystic accounting for $60 \%$ of all cases. Out of 110 cases, 101 cases were reported as tumours of the ovary and 8 cases were reported as tumour like lesions of the ovary on scrape cytology, whereas on imprint cytology, 93 were reported as tumours of ovary and 7 cases were reported as tumour like lesions of ovary. On imprint, 10 cases were inadequate for opinion whereas in scrape smear only 1 case was reported as inconclusive.

Lesions diagnosed by both imprint and scrape smear cytology technique were serous cystadenoma (30\%) followed by mucinous cystadenoma $(0.9 \%)$, mature teratoma (11.8\%), hemorrhagic cyst(7.2\%), granulosa cell tumour (4.5\%), dysgerminoma $(2.73 \%)$, seromucous cystadenoma (4.5\%), mixed germ cell tumour (1.8\%), sex cord-stromal tumour (1.82\%), serous carcinoma (2.7\%), 
mucinous carcinoma $(0.9 \%)$, benign brenner tumour (1.82\%), steroid cell tumour $(0.9 \%)$, endometrioid carcinoma (0.9\%) and Non-Hodgkin lymphoma (0.9\%) (Fig. 1-3).

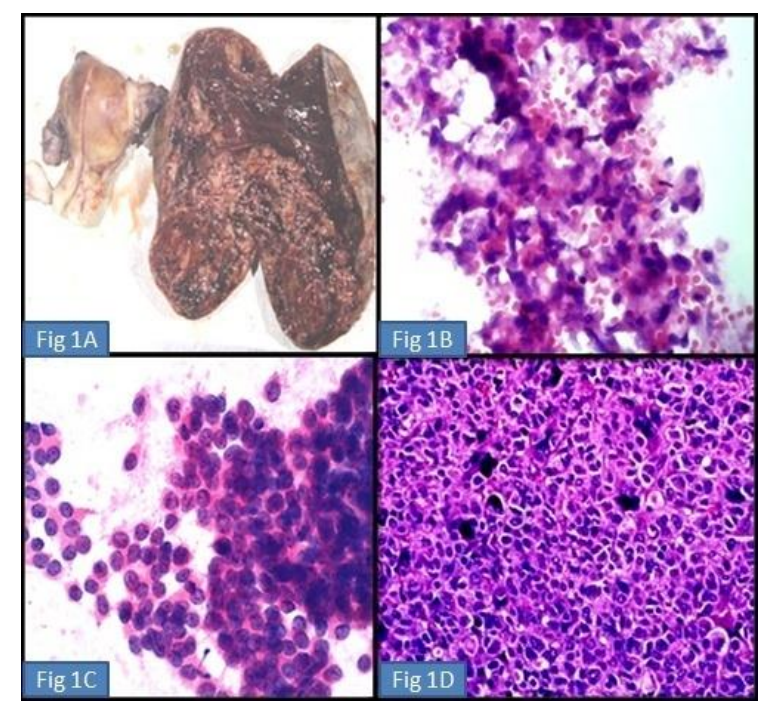

Fig. 1: Photomicrograph of Granulosa cell tumour

1A- Gross photograph, 1B- Imprint cytology, 1C- Scrape cytology, 1D- Histopathology (H\&E, 400X)

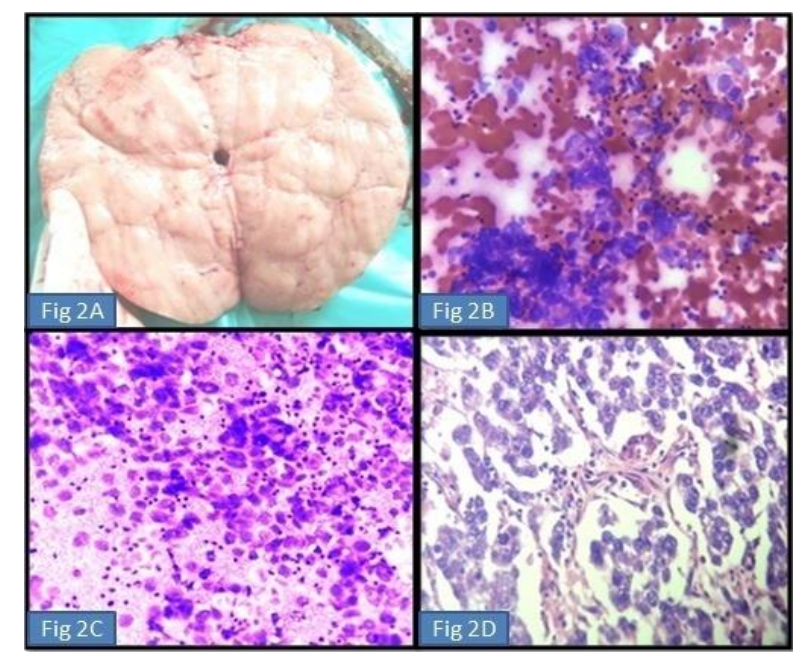

Fig. 2: Photomicrograph of Dysgerminoma

2A-Gross photograph, 2B- Imprint cytology, 2C-Scrape cytology, 2D-Histopathology (H\&E, 400X)

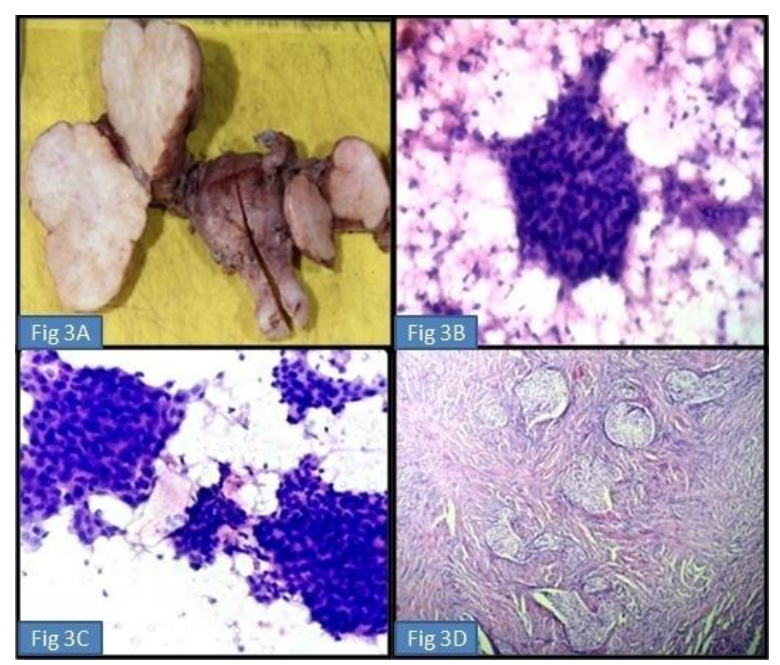

Fig. 3: Photomicrograph of Benign Brenner tumour

3A-Gross photograph, 3B-Imprint cytology, 3C-Scrape cytology, 3D- Histopathology (H\&E, 400X) 
Four cases of benign spindle cell tumour, 1 case of sex cord tumour, 1 case of benign brenner tumour, 1case of hemorrhagic cyst and 1case of Non-Hodgkin lymphoma were reported as inconclusive on imprint smears. Two cases of mixed germ cell tumour were reported as dysgerminoma and mature teratoma on imprint smear cytology.

Comparative study between imprint and scrape cytology showed high cellularity in scrape smear as compared to imprint smear and the statistical difference for cellularity between imprint and scrape was highly significant with $\mathrm{p}$-value less than 0.001 . The architectural pattern was much better in scrape smear as compared to imprint with a highly significant statistical difference with $p$-value less than 0.001, whereas in nuclear features, cytoplasmic staining and background features, the sum of the cumulative score of scrape was slightly higher than imprint smear. However, the difference was not significant statistically (Table 1).

Table 1: Comparison of various cytological features in imprint and scrape cytology

\begin{tabular}{|c|c|c|c|c|c|c|}
\hline \multirow[b]{2}{*}{ Criterias } & \multicolumn{2}{|c|}{ Imprint } & \multicolumn{2}{|c|}{ Scrape } & \multirow{2}{*}{$\begin{array}{c}\text { Mann } \\
\text { Whitney U } \\
\text { test }\end{array}$} & \multirow[b]{2}{*}{$P$ value } \\
\hline & Sum & Mean \pm SD & Sum & Mean士 SD & & \\
\hline Cellularity & 155 & $1.41(1) \pm 0.58$ & 259 & $2.35(2) \pm 0.499$ & $U=1727.5$ & $\mathrm{P}<0.001 \mathrm{HS}$ \\
\hline $\begin{array}{l}\text { Architecture } \\
\text { pattern }\end{array}$ & 164 & $1.49(1) \pm 0.674$ & 253 & $2.30(2) \pm 0.480$ & $U=2288.5$ & $\mathrm{P}<0.001 \mathrm{HS}$ \\
\hline Nuclear features & 158 & $1.22(1) \pm 0.527$ & 160 & $1.09(1) \pm 0.692$ & $U=4761.5$ & $\begin{array}{c}P=0.765 \\
N S\end{array}$ \\
\hline $\begin{array}{l}\text { Cytoplasmic } \\
\text { staining }\end{array}$ & 141 & $1.10(2) \pm 0.673$ & 148 & $0.90(2) \pm 0.524$ & $U=5611.0$ & $\mathrm{P}=0.996 \mathrm{NS}$ \\
\hline $\begin{array}{l}\text { Background } \\
\text { features }\end{array}$ & 221 & $2.59(2) \pm 0.530$ & 229 & $2.33(2) \pm 0.530$ & $U=6050.5$ & $P=0.90 \mathrm{NS}$ \\
\hline
\end{tabular}

NS: Not significant, *HS: Highly significant

Histopathological correlation was done in all 110 cases. Cyto-histological discordance was observed in 17 cases. On histopathology out of 110 cases, 91\% were ovarian tumours and $9 \%$ were tumour like lesions of ovary. Amongst these ovarian tumours, 68 (61.8\%) cases were epithelial tumours, $18(16.4 \%)$ cases were germ cell tumours, $12(10.9 \%)$ cases were diagnosed as sex cordstromal tumours, 1 case each was diagnosed as lymphoma and metastatic carcinoma (0.9\% each).

Out of 68 epithelial tumours, 56 cases were benign, 7 were borderline and 5 were malignant tumours. Among 18 germ cell tumours, 12 were benign and 6 were malignant. All the 10 sex cord-stromal tumours were benign. In tumour like lesions of the ovary, 8 cases were endometriotic cyst and 1 case each of pregnancy luteoma and stromal hyperplasia (Table 2).

Table 2: Comparison between Cytological and Histopathological diagnosis

\begin{tabular}{|c|c|c|c|c|c|c|c|c|}
\hline \multirow{2}{*}{$\begin{array}{l}\text { Cytological } \\
\text { diagnosis }\end{array}$} & \multicolumn{2}{|c|}{$\begin{array}{l}\text { Imprint } \\
\text { diagnosis }\end{array}$} & \multicolumn{2}{|c|}{ Scrape diagnosis } & \multicolumn{2}{|c|}{$\begin{array}{l}\text { Histopathological } \\
\text { diagnosis }\end{array}$} & \multirow{2}{*}{$\begin{array}{l}\text { Chi-square } \\
\text { test }\end{array}$} & \multirow[t]{2}{*}{ P-value } \\
\hline & $\begin{array}{l}\text { No. of } \\
\text { cases }\end{array}$ & $\%$ & $\begin{array}{l}\text { No. of } \\
\text { cases }\end{array}$ & $\%$ & $\begin{array}{l}\text { No. of } \\
\text { cases }\end{array}$ & $\%$ & & \\
\hline Benign & 82 & 7 & 90 & 81.8 & 80 & 72.7 & \multirow{5}{*}{$X^{2}=32.001$} & \multirow{5}{*}{$\begin{array}{c}P<0.001 \\
H S\end{array}$} \\
\hline Borderline & 0 & 0 & 0 & 0 & 7 & 6.3 & & \\
\hline Malignant & 11 & 10 & 11 & 10 & 13 & 11.8 & & \\
\hline $\begin{array}{c}\text { Tumour like lesion } \\
\text { of the ovary }\end{array}$ & 7 & 6.3 & 8 & 7.2 & 10 & 9.0 & & \\
\hline Inconclusive & 10 & 9.0 & 1 & 0.9 & 0 & 0 & & \\
\hline
\end{tabular}


Out of 17 cytohistologically discordant cases, 7 cases of hemorrhagic cyst diagnosed on cytology were concluded as an endometriotic cyst on histopathology. Total 6 cases of mucinous cystadenoma and 1 case of serous cystadenoma diagnosed on cytology were concluded as borderline mucinous cystadenoma and borderline serous cystadenoma respectively on histopathology. A case of immature teratoma was reported as mature teratoma on cytology. One case of stromal hyperplasia diagnosed on histopathology was reported as benign spindle cell lesion and 1 case of pregnancy luteoma diagnosed on histopathology was reported as inconclusive on cytology (Table 3).

Table 3: Distribution of Concordance and Discordance cases between Cytological and Histopathological diagnosis

\begin{tabular}{ccccccc}
\hline $\begin{array}{c}\text { Cytological } \\
\text { diagnosis }\end{array}$ & $\begin{array}{c}\text { Concordance } \\
\text { cases }\end{array}$ & $\%$ & $\begin{array}{c}\text { Discordance } \\
\text { cases }\end{array}$ & $\%$ & $\begin{array}{c}\text { Histopathologi } \\
\text { cal diagnosis }\end{array}$ & $\%$ \\
\hline Benign & 80 & 87 & 0 & 0 & 80 & 72.8 \\
Borderline & 0 & 0 & 7 & 39 & 7 & 6.3 \\
Malignant & 12 & 13 & 1 & 6 & 13 & 11.9 \\
$\begin{array}{c}\text { Tum } \\
\text { of the ovary } \\
\text { Total }\end{array}$ & 0 & 0 & 10 & 55 & 10 & 9.0 \\
Chi-square test & $\mathrm{X}_{2}=103.26 \mathrm{p}<0.001 *(\mathrm{HS})$ & 18 & & 110 & 100 \\
\hline
\end{tabular}

In the present study, the Sensitivity, Specificity, Positive predictive value and Accuracy of overall imprint and

\section{DISCUSSION}

The age group of patients in this study varied from 6 to 75 years with a mean age of 40.5 years. Most of the cases were in the age group of $21-40$ years $(60 \%)$. In the present study, cellularity was better in scrape smear amounting to high cellularity in $36.5 \%$ cases. However, high cellularity was noted in $4.5 \%$ cases on imprint smear. Similar findings were observed by Jain et al. ${ }^{[5]}$ in which it was noticed that cellularity was better with scrape smears than imprint smears.

Comparison of the architectural pattern of imprint and scrape smears showed that in imprint smears the cells were singly scattered in $61 \%$ cases, arranged in clusters in $29 \%$ cases, diffuse sheets in $7 \%$ cases, in $1 \%$ papillary pattern and $2 \%$ cases showed a glandular pattern. Whereas architectural pattern was better appreciated in scrape smears with $62.8 \%$ cases showing cells arranged in clusters, followed by diffuse sheets $(22.7 \%)$, papillary pattern (4.5\%), glandular pattern (3.6\%) and singly scattered cells (1\%). These findings were similar to the study done by Rao et al. ${ }^{[7]}$ The crispness of the nuclear chromatin of the cells was more evident in scrape smears when compared to imprint smears. scrape cytology together was $88 \%, 98.7 \%, 91.6 \%$ and $91 \%$ respectively when compared with histopathology.

Nuclear chromatin was crisp in $91 \%$ cases in imprint smears while in scrape smears $92 \%$ cases showed crisp nuclear chromatin. Similar observations were obtained by Kolte et al. ${ }^{[9]}$.

Cytoplasmic staining was found to be superior in scrape smears as compared to imprint smears. This was comparable to the study done by Mahore et al. ${ }^{[10]}$, Carmen et al. ${ }^{[11]}$ and Soumit et al. ${ }^{[12]}$. The background was clear in $2 \%$ cases in imprint smears and $9 \%$ cases in scrape smears while it was hemorrhagic/ necrotic in $61 \%$ cases in imprint smears and $42.7 \%$ cases in scrape smears. These findings were similar to the observations done by Bandyopadhyay et al. ${ }^{[13]}$, Shahid et al. ${ }^{[14]}$, Sireesha et al. ${ }^{[15]}$ and Bohara et al. ${ }^{[16]}$. In the present study, the overall cumulative scores of imprint and scrape smears showed a highly significant statistical difference concerning cellularity and architectural pattern with a $p$-value of less than 0.001 each. Whereas, the nuclear features, cytoplasmic staining and background features showed no significant statistical difference.

Khan et al. ${ }^{[17]}$ did a comparative study of imprint, scrape cytology and FNAC of breast, lung and colon tumours. 
They concluded that scrape preparations yield high cellularity as compared to imprint preparations and FNAC. The most important qualitative difference that they found was that scrape preparations were more apt, as it exhibits wider variability in the size of the cellular clusters as compared to the imprint. In the present study also cellularity and the architectural pattern was better on scrape as compared to imprint. This difference between imprint and scrape was observed mainly in benign and borderline tumours of the ovary.

Out of 110 cases studied, 93 cases (84.5\%) showed a correlation with histopathology diagnosis. 17 cases (15.5\%) showed discordance. Discordance was observed in tumour like lesions and borderline tumours. Similar findings were found in a study done by Deb et al. ${ }^{[18]}$. These authors mentioned that insufficient sampling of representative areas may be the reason in these cases. $A$ similar explanation holds in the present study also.

In the present study, 10 tumours like lesions of ovary were studied. Out of 10 cases 7 cases were diagnosed as a hemorrhagic cyst on cytology whereas it was diagnosed as an endometriotic cyst on histopathology. This was because of the absence of endometrial cells or stroma or hemosiderin-laden macrophages on cytology smears. Similar findings were found in a study done by Khunamornpong et al. ${ }^{[19]}$, Nagaia et al. ${ }^{[20]}$, Abdelghany et al. ${ }^{[21]}$, and Tushar et al. ${ }^{[22]}$.

In the present study, 6 cases of mucinous borderline tumours and 1 case of the serous borderline tumour were reported on cytology as benign mucinous cystadenomas and benign serous cystadenoma respectively. These cases were misdiagnosed as benign tumour probably because of mild nuclear atypia and epithelial crowding, which was present focally.

All malignant cases reported as serous, mucinous and Endometrioid carcinoma on imprint and scrape cytology were correlated with histopathological diagnosis in the present study. In some studies, it was mentioned that endometrioid carcinoma shows cytological features overlapping with serous carcinoma with smears showing high cellularity comprised of cells arranged in the glandular pattern. Tumour cells are pleomorphic, elongated, having high nucleo-cytoplasmic ratio with the irregular nuclear membrane and moderate eosinophilic cytoplasm. In the present study, we had 1 case of endometrioid carcinoma which was diagnosed on cytology as endometrioid carcinoma and further concluded as endometrioid carcinoma on histopathology.

Out of 12 cases of sex cord-stromal tumours, on cytology 5 cases were diagnosed as granulosa cell tumour and 1 case as steroid cell tumour similar diagnosis was rendered on histopathology. Whereas, 3 cases of fibroma and 1 case of fibroadenoma were diagnosed as benign spindle cell tumour on cytology. 1 case of sex cord tumour with annular tubules and 1 case of the mixed-sex cord-stromal tumour was diagnosed as sex cord tumour on cytology in the present study.

Out of 18 germ cell tumours of the ovary, the commonest tumour was mature teratoma followed by dysgerminoma and mixed germ cell tumour. In all the cases cytohistological correlation was noted. However, 1 case of immature teratoma was misinterpreted as mature teratoma on cytology in the present study; it was diagnosed on histopathology as an immature teratoma. In the present study, in 1 case of Non-Hodgkins lymphoma and 1 case of metastatic invasive lobular carcinoma of breast cytological and histopathological correlation was observed. The sensitivity, specificity, positive predictive value and diagnostic accuracy of overall cytology in this study were $88 \%, 98.7 \%, 91.6 \%$, and $91 \%$ respectively.

\section{CONCLUSIONS}

Imprint and scrape cytology is rapid, safe, simple and inexpensive cytodiagnostic techniques. Imprint and scrape smears ensure good preservation of cytological details in which the cellular architecture, nuclear features and cytoplasmic features can be easily evaluated. Routine utilization of imprint and scrape cytology in ovarian tumour and tumour like lesions can help in increasing the understanding of cytomorphological features of ovarian lesions.

Intraoperative imprint and scrape cytology can act as an adjunct to the frozen section in the diagnosis of tumour and tumour like lesions of ovary. Thus it can guide the surgeon for further proper surgical management of the patient.

\section{ACKNOWLEDGMENTS}

We would like to express my gratitude to the OBG department and also the staff/ faculty of the Department of Pathology for their enormous support during this study. 


\section{CONTRIBUTION OF AUTHORS}

Research concept-Dr. Surekha U Arakeri, Dr. Afra Taqdees Research design- Dr. Surekha U Arakeri, Dr. Afra Taqdees

Supervision- Dr. Surekha U Arakeri

Materials- Dr. Afra Taqdees

Data collection- Dr. Afra Taqdees

Data analysis and Interpretation- Dr. Surekha U Arakeri, Dr. Afra Taqdees

Literature search- Dr. Afra Taqdees

Writing article- Dr. Afra Taqdees

Critical review- Dr. Surekha U Arakeri

Article editing- Dr. Surekha U Arakeri

Final approval- Dr. Surekha U Arakeri

\section{REFERENCES}

[1] Mehar R, Panchonia A, Kulkarni C. Study of imprint smears of various lesions with histological correlation. Int J Med Sci Public Health, 2014; 3: 48688.

[2] Sushma, Panicker S. Imprint cytology in the diagnosis of ovarian lesions. Int J Res Med Sci., 2015; 3: 377074.

[3] Riaz A, Khalid A, Tanwani A. Diagnostic Accuracy of Touch Imprint Cytology in Ovarian Neoplasms. Int J Pathol., 2015; 13: 66-71.

[4] Das C, Mukhopadhyay M, Kumar A, Sengupta M, Dhar G, et al. A Cytohistological correlation in Ovarian tumours. IOSR J Dent Med Sci., 2014; 13: 0105.

[5] Jain R, Jain V, Dutta $S$, Awasthi S, Jain, et al. Role of Intra-operative Cytology in the Diagnosis of Ovarian Neoplasms. Int J Sci Study, 2015; 3: 72-75.

[6] Sardar K, Singh J, Tirkey S. Evaluation of Intraoperative cytology in ovarian tumours. IOSR J Dent Med Sci., 2017; 16: 93-102.

[7] Rao S, Sadiya N, Joseph L, Rajendiran S. Role of scrape cytology in ovarian neoplasms. J Cytol., 2009; 26: 26-29.

[8] Vijayakumar A. Diagnostic Utility of Intraoperative Cytology in the Management of Ovarian Tumours. J Clin Diagn Res., 2013; 7: 1047-50.

[9] Kolte S, Satarkar R. Role of scrape cytology in the intraoperative diagnosis of the tumour. J Cytol., 2010; 27: 86-90.

[10]Mahore S, Bothale K, Joshi A, Wilkinson A, Patrikar A, Gowardhan V, et al. Scrape Cytology in rapid intraoperative diagnosis of tumours. IOSR J Dent Med Sci., 2014; 14: 65-72.
[11]Carmen A, Adela S, Silvia M, Alicia F, Griselle G, Carmen $V$, et al. Contribution of Intraoperative Cytology to the Diagnosis of Ovarian Lesions. Acta Cytol., 2011; 55: 85-91.

[12] Soumit D, Vatsala M, Singh P, Mishra S, Sharma N, et al. Role of Intraoperative Imprint Cytology in Diagnosis of Suspected Ovarian Neoplasms. Asian Pac J Cancer Prev., 2010; 11: 1389-91.

[13]Bandyopadhyay A, Chakraborty J, Chowdhury A, Bhattacharya $A$, Bhattachrya $P$, Chowdhury $M$, et al. Fine needle aspiration cytology of ovarian tumors with histological correlation. J Cytol., 2012; 29: 3540.

[14]Shahid M, Zaheer S, Mubeen A, Rahman K, Sherwani $\checkmark$, et al. The Role of Intraoperative Cytology in the Diagnostic Evaluation of Ovarian Neoplasms. Acta Cytol., 2012; 56: 467-73.

[15] Sireesha A, Triveni B, Sangeeta P, Srilaxmi K, Mallikarjun $S$, et al. Role of imprint cytology in rapid diagnosis of ovarian neoplasms with histopathology correlation. Int Arch Int Med., 2018; 5(11): 56- 62.

[16]Bohara S, Jain S, Khurana N, Shangpliang M, Agarwal S, Gandhi G, et al. Intraoperative cytology of ovarian neoplasms with an attempt to grade epithelial tumors. J Cytol., 2018; 35: 1-7.

[17]Khan N, Afroz N, Aqil B, Khan T, Ahmad I, et al. Neoplastic and nonneoplastic ovarian masses: Diagnosis on Cytology. J Cytol., 2009; 26(4): 129-33.

[18]Deb P, Malik A, Sinha K. Intraoperative scrape cytology: Adult granulosa cell tumor of ovary. J Cytol., 2011; 28: 207-09.

[19] Khunamornpong S, Siriaunkgul S. Scrape cytology of the ovaries: Potential role in intraoperative consultation of ovarian lesions. Diagn Cytopathol., 2003; 28(5): 250-57.

[20]Nagaia Y, Tanakab N, Horiuchic F, Ohkic S, Sekib K, Sekiyab $S$, et al. Diagnostic accuracy of intraoperative imprint cytology in ovarian epithelial tumors. Int J Gynaecol Obstet., 2001; 5: 159-64.

[21]Abdelghany M. Comparative Study between Intraoperative Frozen Section and Scrape Smear Cytology in the Diagnosis of Ovarian Neoplasm. Open J Obstet Gynecol., 2015; 5: 28-35.

[22]Tushar K, Asaranti K, Mohapatra P. Intra-operative cytology of ovarian tumours. J Obstet Gynecol., 2005; 4: 345-49. 
